\title{
DESIGN AND DEVELOPMENT OF AN AGENT-BASED MODEL FOR BUSINESS OPERATIONS FACED WITH FLOOD DISRUPTION
}

\author{
C. LI \& G. COATES \\ Durham University, UK.
}

\begin{abstract}
Small and medium enterprises (SMEs) constitute a major component of the United Kingdom's economy, accounting for $99.9 \%$ of all private sector businesses and approximately 47\% of annual turnover in 2014 [1]. However, these companies can suffer significant financial losses as a consequence of a disruption to business operations, such as a flood event, due to their limited resources and lack of organizational plans. Agent-based modelling is recognized as one approach to enable complex problems in business and social science to be studied. SMEs' preparedness and response to disruptive events can be complex and interactive processes. Hence, agent-based modelling is an appropriate approach to study these processes and identify any emerging phenomena. With the aim of providing guidance for SMEs regarding how to better prepare and respond to the challenges faced when flooding occurs in the future, an agent-based model (ABM) is currently being designed and developed to represent and simulate SMEs' existing and potential behaviours immediately prior to, during and in the short-term aftermath of a flood event. This paper describes preliminary work on the ABM's development undertaken including the design of the various agents represented, the rules governing agent behaviours, the attributes of agents and the environment in which they operate. The basis of the ABM design draws on a range of sources including semi-structured interviews with SMEs which have experience of significant flooding, guidelines from the Environment Agency and local councils, business continuity management systems' requirements (ISO223301) and academic literature. Further, the paper discusses performance metrics of SMEs which are adopted to assess the level of continuity of business operations in the model.

Keywords: agent-based model, business disruption, flooding, resilience, SME.
\end{abstract}

\section{INTRODUCTION}

Small and medium enterprises (SMEs) constitute a major component of the United Kingdom's economy. Approximately, $99.9 \%$ of all private sector businesses are SMEs, accounting for $47 \%$ of private sector turnover in the UK at the start of 2014 [1]. Disruptions to businesses often result in a significant impact on the regional economy and a wider impact on the national economy. According to the Environment Agency (EA), the 2007 floods caused a $£ 740$ million loss to UK businesses [2]. SMEs are known to have limited resource [3,4], a lack of organizational slack [5] and a lack of contingency/disaster recovery plans [6,7]. Therefore, the capability of adapting to cope with flooding becomes vital in terms of maintaining operations.

SESAME is a research project aimed at studying and enhancing SMEs' organizational resilience to flood events [8]. The purpose of this paper is to present the preliminary design of an agent-based model (ABM), which is to be used to simulate SMEs' existing and potential behaviours immediately prior to, during and in the short-term aftermath of a flood event. The ABM offers opportunities to obtain an understanding of the resilience of SMEs at an organizational level as well as the SME community as a whole. The paper describes the design in the context of the model based on a range of sources including interviews with SMEs which have experience of significant flooding, guidelines from the EA and local councils, business continuity management systems' requirements (ISO223301) and academic literature. Further, details are presented of agents and the interaction network of agents, simulation scenario design and evaluation of SMEs' performance. 


\section{RELATED WORK}

Limited research has been done to understand SMEs behaviours and strategies when facing floods. Previous research investigates the preparedness and adaptions of businesses in the UK when facing floods [9] and preparedness of businesses in Germany [10]. Factors identified as being related to the preparedness of a business include EA warnings, property and business insurance, resilient fittings, temporary and permanent flood installations, alternative location, alternative power source, alternative fuel source, data backup, emergency plan and business disruption plan [9]. Studies show that the majority of SMEs are inadequately prepared for floods and take a long time to recover or never reopen after floods [11,12], while case studies in [7] provide an insight into the ability that some SMEs have in the recovery from a major flood event.

Agent-based modelling has gained increasing attention over recent years and has been applied to diverse fields such as business, biology, public policy and social science [13]. It is a tool that is commonly used to study and understand complex systems. SMEs' preparedness to flood events and recovery post flooding are complex processes. As it is difficult to analyse and model such processes using traditional approaches, agent-based modelling is seen as an appropriate means to study this problem. To date, several existing ABMs simulate either flood risk related to individuals $[14,15]$ or business aspects of SMEs [16,17]. For example, Blackmore et al. [16] develops an ABM to understand the process of growth and innovation that evolves in SMEs over time. Another ABM [17] is developed to analyse supply chains in context of SMEs. Despite this work on ABM in the context of businesses, modelling SMEs in the context of disruptive events, in particular flooding, remains unexplored.

\section{AGENT-BASED MODELLING AND SIMULATION}

An overview of the agent-based modelling and simulation framework is shown in Fig. 1. The framework consists of a pre-processing module, agent-based modelling and simulation and a post-processing module.

In pre-processing, the virtual geographical environment (VGE) captures all the SMEs in a defined geographical area and the dynamic flood model generates inundation data against a timeline which feeds into the ABM [18]. In the context of this paper, hydrodynamic modelling for a 1 in 1000 year event has been carried out in relation to the Lower Don Valley region of Sheffield in the UK. A 1D-ISIS and 2D-TUFLOW hydraulic model of the River Don provided by the

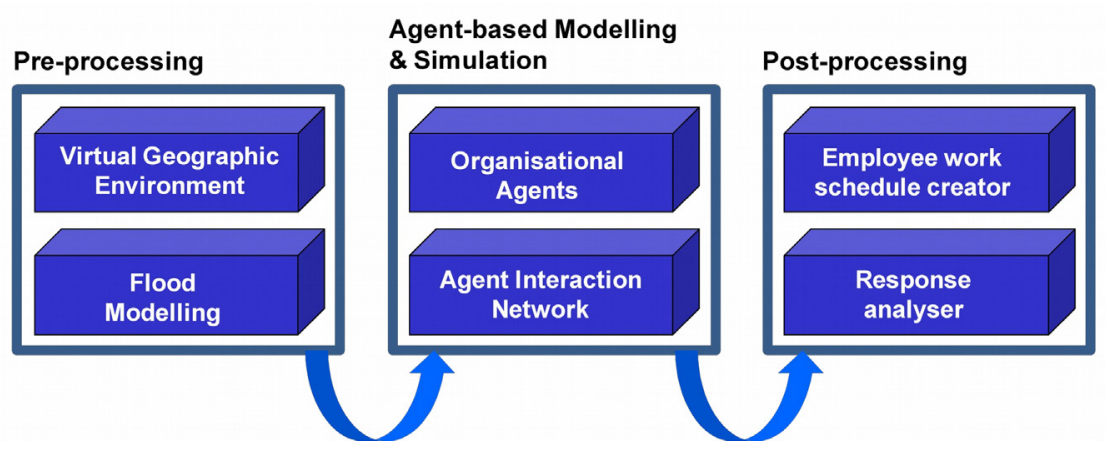

Figure 1: An overview of agent-based modelling and simulation framework. 
Environment Agency has been used. More specifically, the 1D ISIS model represents the River Don channel and the 2D TUFLOW model represents the surrounding floodplain and highly developed urban areas where flood mechanisms are more complex. Buildings have been represented in 2D model domains using high roughness areas and both the 1D and 2D models are dynamically linked. The ABM consists of agents and agent networks. Various types of agents are designed in the model, whereas agent networks represent SMEs' social networks. In post-processing, the output data of the simulation are analysed to determine the level of influence of different behaviours on business operations.

As referred to earlier, the design of the ABM is based on interviews with stakeholders, guidelines from the EA [19] and practitioners [20,21], business continuity management systems' requirements (ISO 223301) [22] and academic literature (e.g. [9,10]). In this section, we will present the design of ABM.

\subsection{Types of agents}

To study SMEs' preparedness and responses to flood events, several types of agents have been designed and are currently included in the model:

- SME agents constitute the majority of agents in the ABM.

- Flood agents (one for each SME agent) represent the dynamic flood status in a specific geographical location, which maps to the location of the corresponding SME agents' premises.

- An Environment Agency (EA) publishes flood warnings and flood alerts, which can play an important role in flood risk management for businesses.

- A Met Office agent broadcasts weather reports and flood warnings, which if received by SME agents may accelerate their response to a flood event.

The behaviour of SME agents is influenced by the interactions between agents in the simulation environment.

\subsection{Agent attributes}

Agent attributes, in addition to behaviours, shape the 'personality' of an agent. Since SMEs stem from a wide range of business sectors, their attributes are categorized as generic, which all SME agents have in common, or specific, which SMEs have within a particular business sector. Some generic attributes of SME agents are obtained from the VGE output, including company name, business code according to the National Land Use Database classification, location and identification number. Other generic attributes of a business, not obtained from the VGE, include turn over, the number of employees, premises details including the number of floors and the number of buildings, and indications such as whether or not the SME owns the premises, is multi location, has an emergency-plan, has flood experience, is fully insured, is registered to receive flood warning and has cash available to aid recovery. Some other generic attributes are required to enable SME agents to communicate in networks to exchange information with other SME agents and other types of agents. These attributes include a list of neighbours as well as useful contacts such as service companies (e.g. electricians, plumbers). Apart from the generic attributes, specific attributes of SME agents vary depending on business type. Initially, this aspect of the ABM has focused on manufacturing SMEs. Specific attributes for manufacturing SMEs include stock levels and indications as to whether or not the business has engineers onsite, has an electricity generator and has pumps, all of which may 
aid and speed-up recovery. Other business sectors will be designed and implemented in later stages of the project.

Flood agents provide inundation data at different times in and around the premises of SME agents. A flood agent has attributes including location, and depth of water in the building and on roads adjacent to the building. The inundation at different times is modelled and calculated in the flood model and fed into the ABM. The SME agents interact with flood agents at each time step to obtain updates of the depth of water attribute and thus make decisions on which actions to take in response to the current flood situation. The EA agent and Met Office agent both have an alert table and a message sender to send/publish flood warnings and weather reports, respectively. The EA agent has a list of all the subscribers who register for the flood warnings, and only sends alerts to subscribers, whereas the Met Office agent sends weather reports and flood warnings via general media.

\subsection{Agent behaviours}

Behaviours of SME agents vary depending on business sector. Further, even SME agents from the same business sector can act differently in responding to a flood event according to their available resources. For example, a manufacturing SME agent could have behaviours as follows: lift up Information Technology (IT) equipment, seal doors, cut-off electricity, evacuate, contact electricians, restore power supply, hire electricity generator, contact insurance company, contact landlord, catalogue damage, clean up by employees/contractors, arrange work to be done at other unaffected locations or on floors above ground level, direct landlines to company mobiles, contact customers, contact suppliers, source money if the SME is not cash-rich, dry/fix machinery/equipment, move stock and clean stock. All behaviours are categorized into (i) pre- and during-flood stage and (ii) post-flood stage. Behaviours in the pre- and during-flood stage include saving fragile items at high risk of being damaged by the water. Behaviours in the post-flood period focus on recovery from the impact of the flood in an operational sense, e.g. working to restore production capability.

SME agents make decisions on what actions to take next based on information such as flood warnings (if received) and depth of water, leading to a prioritized sequence of behaviours to enact. Allocating a priority to each behaviour ensures that one with a higher priority will be executed first when more than one behaviour could be enacted at the same time. Also, each behaviour is considered in terms of whether or not it can be enacted before the flood water recedes from the premises, whether it can be enacted by one employee or more than one employee and whether it is generic or specific to a particular type of SME. For example, consider a manufacturing SME agent which does not subscribe to EA alerts. Such an SME may only start to lift up and move equipment when it is apparent that the flood water will enter the premises or when they watch weather reports before the water enters the premises. Also, if there are engineers on site and useful materials are available to protect the building from flooding, such as enabling doors to be sealed, these individuals can attempt to prevent water entering premises. Furthermore, if it is safe to leave the premises, evacuation would be executed. However, if roads are closed due to the inundation, employees may be stranded and would need to wait until the roads are safe to use before leaving the premises. Post flooding, the SME has to work on restoring the power supply if there is no power at the premises, clean up, inform its insurance company, contact customers and suppliers, dry and fix important machinery, move and clean stock if it is flooded, and so on.

Other types of agents have simpler behaviours compared to SME agents. Flood agents update dynamically the depth of water associated with their corresponding SME agent's premises and adjacent road. The EA agent in the model publishes flood warnings containing information of warning 
levels to subscribers. The Met Office agent broadcasts weather reports and flood warning to the public.

\subsection{Agent networks}

Case studies undertaken in the SESAME project have found that some SMEs are able to utilize internal resources, access external resources and leverage social capital forming the platform for effective response and recovery [7]. To simulate SMEs searching and accessing resources through their social networks, several networks have been considered.

- Publish-subscribe flood warnings between the EA agent and SMEs agents: The EA agent is responsible for publishing flood alerts and warnings. Only SMEs which subscribe to this service will receive the alert and warning messages.

- Weather reports and flood warnings are broadcasted by the Met Office: All SMEs are able to access information about these weather reports and flood warnings providing they are connected to media channels such as news online, television and radio.

- Relationships with neighbours: Neighbouring SMEs may exchange information about the flood before flooding happens and help each other during and after the flood, e.g. share warehouses unaffected by the flood.

- Relationships with engineering services: SMEs which have pre-existing relationship with engineering service companies (e.g. electricians and plumbers) can speed-up the resumption of operations and shorten the length of business disruption.

- Mutual aid agreement with other SMEs: Establishing mutual aid agreement between SMEs will help them minimize the business disruption caused by floods [22].

- Outsourcing [22]: SMEs disrupted by flooding may outsource their own work to other businesses unaffected by the flood thus guaranteeing continuity of the delivery of their services/products to their customers.

\section{SIMULATION SCENARIOS}

To study SME's response to flood events, two simulation scenarios will be considered. The first scenario simulated, which is currently under development, is based on existing behaviours of SMEs with experience of flooding. The second scenario to be designed will incorporate behaviours suggested by literature as well as those identified by SMEs in light of their prior experience of flooding. Each simulation will represent a duration of 15 days commencing from the time at which inundation first occurs. An aim of these simulations is to identify the key factors and processes undertaken by SMEs which enable them to respond efficiently to a flood event, and thus accelerate recovery.

\subsection{Scenario 1: SMEs with low preparedness}

The first scenario to be modelled focuses on SME agents exhibiting behaviours akin to those of businesses with experience of flooding. More specifically, actions and behaviours were modelled of SMEs with experience of the significant flooding in 2007 in the Lower Don Valley region of Sheffield. Analyses of interview transcripts with a number of these businesses, which covered a range of sectors, revealed details of what they did when preparing for, responding to and recovering from the impact of a flood event. 


\subsection{Scenario 2: SMEs with enhanced preparedness}

In the second scenario to be simulated, SME agents' behaviours will be designed based on what these businesses would do differently in terms of preparation and response, and/or in addition to what was done, as a result of their experience of flooding in 2007. Again, the behaviours identified to be modelled stem from SMEs' reflections of their own experience of flooding as indicated in the interview transcripts referred to in Section 4.1. In addition to these changes in behaviour, recommended preparatory actions for SMEs published by the EA and other government bodies will be modelled. A series of behaviour changes and recommended behaviours will be modelled including registering to receive EA flood warnings, improving the telephone system (e.g. emergency mobiles, diversion service), raising the level of equipment, stocks and documents, moving stock to other safer places, keeping sandbags on site, building bund walls, storing and backing-up all documentation electronically, preparing an emergency plan or business continuity plan, and adopting basic strategies for protecting the property such as sealing external brickwork with water proofing substances. In the simulations, both reflective behaviour changes and recommended behaviours are considered to (i) enable a comparison to be made with the results obtained from scenario 1 and (ii) establish which factors are most influential in facilitating an effective and efficient approach to dealing with flooding, thus informing the preparedness of SMEs to future disruptive events of this nature.

\section{MEASUREMENT OF SMES' PERFORMANCE}

The current version of the ABM is aimed at enabling an investigation of the impact of organizational behaviours in relation to flooding. Evaluating the performance of SMEs and comparing the results with and without behaviour changes/recommendations allows such an investigation. However, to date no existing work has been carried out regarding the evaluation of SMEs performance when faced with a flood event. This section presents a suggested measurement of SMEs' performance after experiencing a flood event, which will be developed further as the research progresses, and an indication of the preliminary output of the model.

\subsection{Performance evaluation of SMEs in the simulation}

Currently, in the ABM, the impact of flooding on the performance of a SME is related to disruption time which starts from the point at which the flood causes an interruption to the SME's normal operation and ends when the company returns to normal operation. In this work, normal operation is defined as the state in which the SME has fully restored its pre-flood level capability of manufacturing products and/or delivering services. Specifically, the metric termed operation level $(O L)$ is adopted to evaluate the performance of a SME in ABM simulations. As a result of a flood event, each SME has a list of $n$ tasks $\left\{T_{0}, T_{1}, T_{2}, \ldots, T_{n}\right\}$ to complete in order to return to normal operation, each of which has an associated number of man hours $\left\{H_{0}, H_{1}, H_{2}, \ldots, H_{n}\right\}$. Therefore, the total number of man hours required to be undertaken in order for the SME to resume normal operation,

$$
H_{\text {total }}=\sum_{i=0}^{n} H_{i}
$$

Thus, the operation level,

$$
O L=\frac{H_{\text {completed }}}{H_{\text {total }}}
$$


where $H_{\text {completed }}$ is the number of completed man hours of tasks at the point in time under consideration during the recovery period. For example, consider a SME with a list of tasks which will take 550 man hours in total to complete. At the point in time when the SME's employees have worked on these tasks for 200 hours, the operation level is $36.4 \%$, calculated from $200 / 550$.

At any point in time, the operation level of a SME depends on the level of human resources available, along with other resources needed, and the allocation strategy of these resources to the tasks to be undertaken. Furthermore, a task can be undertaken only when there are available employees who can work on it and whether the employees have the means to carry out the task. For example, if a SME does not have power in the premises due to flooding, tasks such as clean-up and clean/fix machinery cannot be carried out, even if employees are available. As a result of the conditions and constraints to carry out tasks, the strategy that a SME adopts to allocate its human resources affects the progress of recovery. Maximizing the utilization of the human resources while considering the conditions and constraints will speed up the recovery. In addition to resources, a SME's operation level depends on the amount of disruption and/or damage caused by the flood water. In the simulations, the higher the depth of water in a premises, the more damage the it causes; thus, the more man hours needed to repair the damage, which results in longer time required to return to normal operation.

\subsection{Illustrative results}

An initial simulation of the ABM, focusing on manufacturing SMEs, has been set up and executed with the following assumptions:

- Manufacturing SME agents have specific attributes including stock levels, products manufactured and an indication as to whether the company has an electricity generator or not.

- Manufacturing SME agents' generic attributes are assigned within the ranges sampled from SME interview data, e.g. number of employees.

- Manufacturing SME agents have specific behaviours including dry and fix machinery, move stocks to a safer place, and clean stock.

- Some manufacturing SME agents subscribe to EA alerts and watch news and weather reports, while others do not.

- All employees of a manufacturing SME can work on tasks regardless of the type of task.

Illustrative simulation results, as processed by the post-processing module in the framework presented in Fig. 1, are shown in Fig. 2.

Figure 2 presents an example employees' work schedule of a manufacturing SME agent, with 17 employees. Future development of the post-processing module will include operation level being plotted against the same timeline as the employees' work schedule. As shown in Fig. 2, the SME operates from 8 am to $6 \mathrm{pm}$ on each working day, with only the initial four days of the simulation shown. Employees in this SME were allocated efficiently to tasks as they are rarely idle throughout the simulation period. Note that black bars signify out of work hours (6 pm until $8 \mathrm{am})$ and it is during this period that the flood occurs (after a full working day of 'production' in the first day 1 simulated). On the second day, the SME started to allocate those employees attending work to restore the production capability. For example, employee 0 worked on 'direct landline', 'restore power', 'contact suppliers' and 'contact customers' all of which took a relatively short time to complete due to other employees also being allocated to undertake these tasks. Among these four tasks mentioned, 


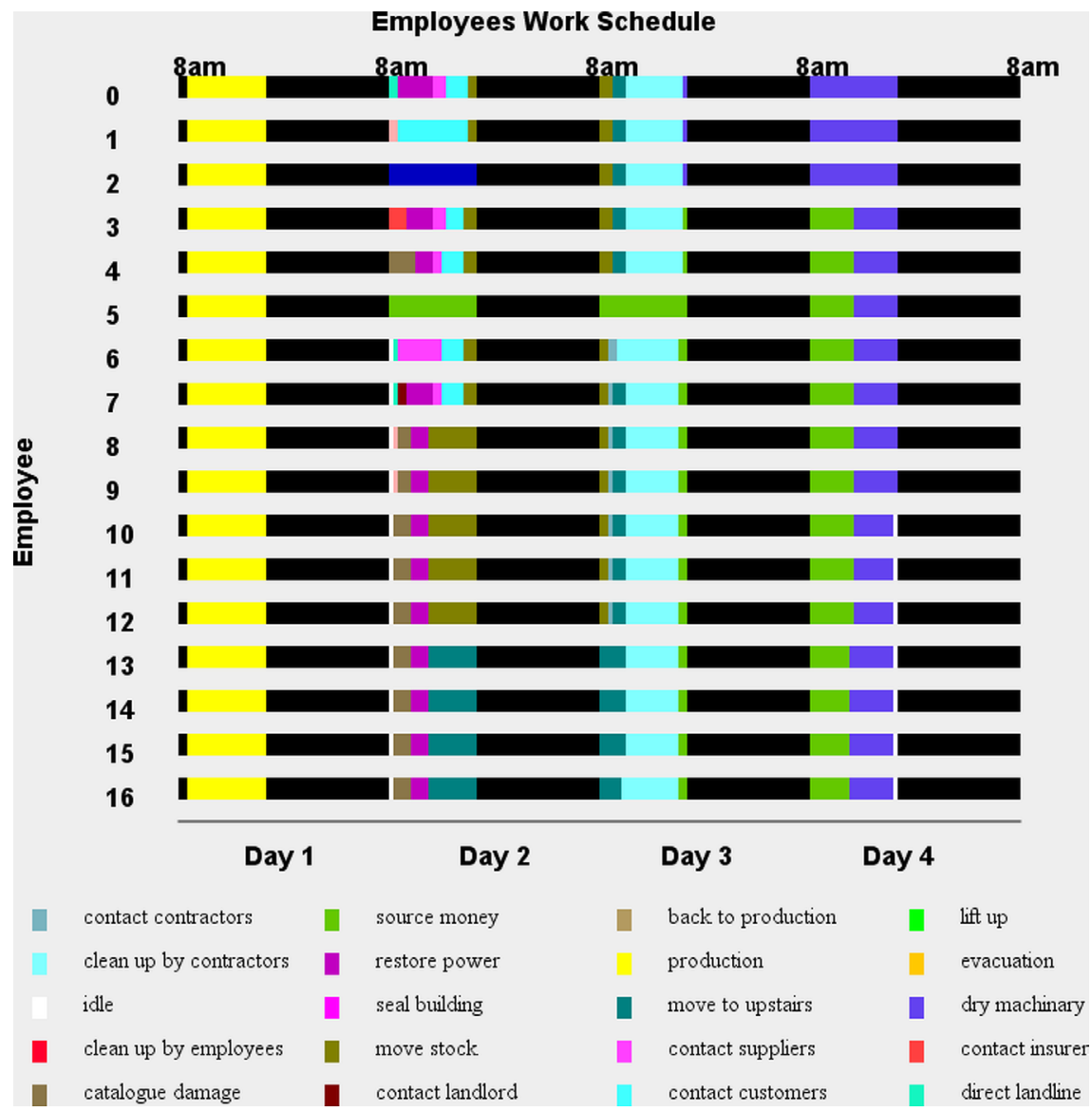

Figure 2. Employees work schedule in a SME.

'direct landline' and 'restore power' have higher priority because they must be completed before other tasks can be undertaken, i.e. dependency relationships exist between tasks. On the third day, due to there being damp stock and the 'move stock' task had not been completed by the end of the second day, employee 0 was allocated to continue to work on this task. Further, since the premises had an upstairs level, which allowed a temporary office to be set-up, employee 0 was allocated to 'move to upstairs' after 'move stock' was completed. Subsequently, employee 0 waited for a contractor to clean up (i.e. 'clean up by contractors' in Fig. 2), which is arranged by the insurance company. On the fourth day, employee 0 worked on 'dry machinery' for the entire day, after which the SME returned to normal operation. By plotting the employees' work schedule, the effect of different resource allocation strategies in the recovery period can be compared and studied.

\section{CONCLUSION AND FUTURE WORK}

This paper presents an ABM currently under design and development, which will be used to investigate SMEs preparedness, response and recovery to flood events. Evaluation of SMEs performance in the immediate response and recovery period after floods is discussed and an illustration of how 
results will be presented is given. To our knowledge, this work is the first model to study SMEs preparing for and responding to flood events. The ABM will offer an opportunity for SMEs to understand how preparedness behaviours enhance flood resilience and reduce the economic impact. In future, as more business sectors will be introduced and developed in the ABM, diverse scenarios in different business sectors are to be designed and implemented to identify and investigate the key factors to improve the flood resilience of SMEs.

\section{ACKNOWLEDGEMENT}

The authors thank the UK Engineering and Physical Science Research Council under grant EP/ K012770/1.

\section{REFERENCES}

[1] Department of Business, Innovation and Skills, Business Population Estimates for the UK and Regions 2014, Department of Business, Innovation and Skills, pp. 1-16, 2014. Available at: https://www.gov.uk/government/uploads/system/uploads/attachment_data/file/377934/bpe_2 014_statistical_release.pdf (accessed on 21 July 2015).

[2] Chatterton, J., Viviattene, C., Morris, J., Penning-Rowsell, E.C. \& Tapsell, S.M., The Costs of the Summer 2007 Floods in England, Environment Agency: Bristol, 2010.

[3] Van Gils, A., Management and governance in Dutch SMEs. European Management Journal, 23, pp. 583-589, 2005. doi: http://dx.doi.org/10.1016/j.emj.2005.09.013

[4] Sullivan-Taylor, B. \& Branicki, L., Creating resilient SMEs: why one size might not fit all. International Journal of Production Research, 49, pp. 5565-5579, 2011. doi: http://dx.doi.org/ 10.1080/00207543.2011.563837

[5] Grunert, J. \& Norden, L., Bargaining power and information in SME lending. Small Business Economics, 39, pp. 401-417, 2012. doi: http://dx.doi.org/10.1007/s11187-010-9311-6

[6] Jones, K. \& Ingirige, B., Extreme weather events and business continuity planning. CIB W70 International Conference in Facilities Management, Edinburgh, 16-18 June 2008.

[7] Li, C., Coates, G., Johnson, N. \& McGuinness, M., Designing an agent-based model of SMEs to assess flood response strategies and resilience. XIII International Conference on Flood Resilience, Zurich, Switzerland, 2015.

[8] Coates, G., Hawe., G.I., McGuinness, M., Wright, N.G., Guan, D., Harries, T. \& McEwen, L., A framework for organisational operational response and strategic decision making for long term flood preparedness in urban areas. Proceedings of the 3rd International Conference on Disaster Management, A Coruña, Spain, 9-11 July 2013.

[9] Bhattacharya-Mis, N. \& Lamond, J., An investigation of patterns of response and recovery among flood-affected businesses in the UK: a case study in Sheffield and Wakefield. WIT Transactions on Ecology and The Environment, 184, pp. 163-173, 2014.

[10] H. Kreibich, I. Seifert, A. Thieken, B. Merz, D. Proverbs, C. Brebbia, et al., Flood precaution and coping with floods of companies in Germany. In Proceedings of the 1st International Conference on Flood Recovery, Innovation and Response (FRIAR), London, UK, 2-3 July 2008, pp. 295-302. doi: http://dx.doi.org/10.2495/FRIAR080281

[11] Crichton, D., Flood risk \& insurance in England and Wales: are there lessons to be learned from Scotland? Benfield Hazard Research Centre: London, 2005.

[12] Crichton, D., Climate Change and its Effects on Small Businesses in the UK. Axa Insurance: Paris, 2006. 
[13] Heath, B., Hill, R. \& Ciarallo, F., A survey of agent-based modeling practices (January 1998 to July 2008). Journal of Artificial Societies and Social Simulation, 12, p. 9, 2009.

[14] Dawson, R.J., Peppe, R. \& Wang, M., An agent-based model for risk-based flood incident management. Natural Hazards, 59, pp. 167-189, 2011. doi: http://dx.doi.org/10.1007/s11069011-9745-4

[15] Liu, Y., Okada, N., Shen, D. \& Li, S., Agent-based flood evacuation simulation of life-threatening conditions using vitae system model. Journal of Natural Disaster Science, 31, pp. 69-77, 2009. doi: http://dx.doi.org/10.2328/jnds.31.69

[16] Blackmore, K., Bossomaier, T., Jarratt, D. \& Nesbitt, K., Intelligent agent framework for modelling the evolution of small and medium sized enterprises. 8th Australian and New Zealand Conference on Intelligent Information Systems, 10-12 December 2003, Macquarie University, Sydney, Australia.

[17] Tounsi, J., Habchi, G., Boissière, J. \& Azaiez, S., A multi-agent knowledge model for SMEs mechatronic supply chains. Journal of Intelligent Manufacturing, 23, pp. 2647-2665, 2012. doi: http://dx.doi.org/10.1007/s10845-011-0537-1

[18] Coates, G., Hawe, G.I., Wright, N.G. \& Ahilan, S., Agent-based modelling and inundation prediction to enable the identification of businesses affected by flooding. Proceedings of the 4th International Conference on Flood Recovery, Innovation and Response, Poznan, Poland, 18-20 June, 2014. doi: http://dx.doi.org/10.2495/friar140021

[19] Environment Agency, Would Your Business Stay Afloat? A Guide to Preparing Your Business for Flooding, Environment Agency. Available at: https://www.gov.uk/government/uploads/ system/uploads/attachment_data/file/410606/LIT_5284.pdf (accessed 21 July 2015).

[20] Wiltshire County Council, Business Continuity Guide for Small Businesses, Wiltshire County Council, 2006. Available at: http://www.wiltshire.gov.uk/business-continuity-guide-for-smallbusinesses.pdf (accessed 21 July 2015).

[21] Association of British Insurers. Insurance for Small Businesses: A Guide to Protecting Your Business, Association of British Insurers. Available at: https://www.abi.org.uk/ /media/Files/ Documents/Publications/Public/Migrated/Liability/Insurance\%20for\%20Small\%20Businesses\%20a\%20guide\%20to\%20protecting\%20your\%20business.pdf (accessed 21 July 2015)

[22] International Organization for Standardization, ISO 22301 Societal Security - Business Continuity Management Systems, International Organization for Standardization: Geneva, Switzerland, 2012. 